\title{
ИЗУЧЕНИЕ ГЕНЕТИЧЕСКОГО РАЗНООБРАЗИЯ ГЕНОТИПОВ ДИКОГО ГРАНАТА (PUNICA GRANATUM L.) АЗЕРБАЙДЖАНА С ИСПОЛЬЗОВАНИЕМ MАРКЕРОВ ISSR
}

\section{S.V. Hajiyeva}

\section{THE STUDY OF GENETIC DIVERSITY OF WILD POMEGRANATE (PUNICA GRANATUM L.) GENOTYPES OF AZERBAIJAN USING ISSR MARKERS}

\author{
Гаджиева Сабина Вахид - асп., науч. сотр. \\ отдела биотехнологии Института генетических \\ ресурсов Национальной Академии Наук Азербай- \\ джана, Азербайджанская Республика, г. Баку. \\ E-mail: sabinahajiyeva@mail.ru
}

Цель исследования - изучение генотипов дикого граната Азербайджана из 6 географрических районов. Исследование проводилось в лаборатории биотехнологии Института генетических ресурсов Национальной Академии Наук Азербайджана в 2015-2018 г2. Объектом для исследования явились 90 образцов граната, фррагменты листьев которых были собраны из 6 районов Азербайджана. Было идентифицировано 110 ПЦР-фрагмента, из них 86 оказались полиморфными. Число амплифицированных фррагментов на локус варьировало от 5 до 10, а диапазон длин полученных фррагментов находился в пределах 100 1100 п.н. В среднем один праймер инициировал синтез 7,8 фррагментов. Количество полиморфрных фррагментов ДНК варьировало от 3 до 9. Минимальное число полиморфнных фррагментов идентифицировалось праймерами UBC 827 и UBC 857, среднее число которых составило 6,1. В зависимости от праймера количество полиморфных локусов колебалось в пределах 57-100\%, уровень полиформизма в среднем составил 78 \%. Был вычислен индекс генетического разнообразия (ИГР) по каждому ISSR локусу, среднее значение которого составило 0,77. С помощью праймеров IS15, UBC811 и HB14 вычислены наиболее высокие значения индекса (0.92, 0.90 и 0.90) coответственно. Кластерный анализ позволил сгруппировать изученные образцы в 5 основных группах. Индекс генетического сходства варьировал от 0,03 до 1,00. Результаты исследова-
Hajiyeva Sabina Vahid - Post-Graduate Student, Staff Scientist, Department of Biotechnology, Institute of Genetic Resources, National Academy of Sciences of Azerbaijan, Azerbaijan Republic, Buku. E-mail: sabinahajiyeva@mail.ru

ния показывают, что разнообразие существует в зародышевой плазме дикого граната, собранной в Азербайджане. С тех пор наблюдалось большое количество генетического разнообразия в растениях, что в дальнейшем привело к легкой адаптации растений к различным условиям окружающей среды. Исследования по молекулярному анализу различных генотипов могут также привести к установлению филогенетических отношений внутри генотипов, принадлежащих к одному или разным местам. Это также поможет понять процесс одомашнивания в ближайшем будущем.

Ключевые слова: дикий гранат (Punica granatum L.), молекулярные маркеры, ISSRпраймеры, генетический полиморфизм, кластерный анализ.

The research objective was studying the genotypes of wild pomegranate of Azerbaijan from 6 geographical areas. The research was conducted in the Laboratory of Biotechnology of Institute of Genetic Resources of National Academy of Sciences of Azerbaijan in 2015-2018. The objects for the research were 90 samples of pomegranate which fragments of leaves collected from 6 regions of Azerbaijan. In total 110 PCR fragments were identified, of which 86 were polymorphic. The number of amplified fragments per locus varied from 5 to 10 , and the fragments obtained were in the size range of 100-1100 bp. On average, one primer initiated the synthesis of 7.8 fragments. The quantity of polymor- 
phic fragments of DNA varied from 3 to 9 . The minimum number of polymorphic fragments was identified by primers of UBC 827 and UBC 857 which average number made 6.1. Depending on the primer the quantity of polymorphic loci fluctuated within 57$100 \%$, the level of polymorphism averaged $78 \%$. The index of genetic variety (IGV) on each ISSR to the locus which average value made 0.77 was calculated. By means of the primers of IS15, UBC811 and HB14 the highest values of the index $(0.92,0.90$ and 0.90), respectively were calculated. The cluster analysis allowed dividing the studied samples in 5 main groups. Genetic similarity index ranged from 0.03 to 1.00. The results of the research show that the variety exists in germinal plasma of wild pomegranate collected in Azerbaijan. Since then a large amount of the genetic variety in plants was observed that further led to easy adaptation of plants to various conditions of the environment. The researches on molecular analysis of various genotypes can also lead to the establishment of phylogenetic relations in the genotypes belonging to one or different places. It will also help to understand the domestication process in the near future.

Keywords: pomegranate (Punica granatum L.), molecular markers, ISSR- primers, genetic polymorphism, cluster analysis.

Введение. Дикий гранат (Punica granatum L.) хорошо адаптирован к широкому спектру климатических условий и поэтому имеет широкое географическое распространение. Естественный рост диких гранатовых деревьев наблюдается в Центральной Азии, включая Иран, Афганистан и Южный Кавказ, а также в северо-западной Индии [1]. Растения граната характеризуются высокой адаптивностью к абиотическому стрессу, благодаря чему он широко возделывается в тропических и субтропических районах Средиземноморья (Египет, Марокко, Испания, Турция и Тунис) [2].

Географическое расположение и разнообразие почвенно-климатических условий Азербайджана, являющегося центром образования некоторых видов растений, способствовало богатому разнообразию культурных растений. История страны неразрывно связана с культурой возделывания граната, имеющего большой ареал распространения и богатое биологическое разнообразие из-за благоприятных условий выращивания. Гранат - один из широко культивируемых плодовых растений. Не удивительно, что гранат считается одним из национальных символов Азербайджана. Поэтому изучение генетического разнообразия растений граната, идентификация генотипов представляет большой научный интерес. Растения граната в основном изучались по морфологическим признакам [3]. Эти показатели, являясь важными при идентификации образцов, не позволяют оценить большое количество растений, подвергнутых действию окружающей среды [4]. Для оценки этой культуры и во избежание дублирования помимо морфологических признаков необходимо охарактеризовать каждый генотип, изучив его генетический профиль с помощью методов, основанных на ДНК-маркерном анализе $[5,6]$.

Цель исследования: изучение генотипов дикого граната Азербайджана из 6 географических районов.

Результаты исследований позволят проводить селекционные работы в различных направлениях.

Материал и методы исследования. Исследование проводилось в лаборатории биотехнологии Института генетических ресурсов Национальной Академии Наук Азербайджана в 2015-2018 гг. Объектом для исследования явились 90 образцов граната, фрагменты листьев которых были собраны из 6 районов Азербайджана (табл. 1).

Молекулярный анализ. При выделении геномной ДНК брали навески по 0,1 г из свежесобранных листьев, согласно ЦТАБ (цетилтриметиламмониум бромид) протоколу, предложенномy Doyle et Doyle с некоторыми модификациями [7]. Концентрацию и степень чистоты молекулы ДНК определяли с помощью НаноДропа (Thermo, NANO DROP, 2000). Конеч-ный объем реакционной смеси образца для ПЦР составлял 20 мкл, содержащей 2 мкл 10хПЦР буфрера; 2 мкл смеси dNTP (5 мM); 1,5 мкл $\mathrm{MgCl} 2$ (50 мМ); 2 мкл каждого праймера (15 пмоль/мкл); 0,1 мкл фермента Таq полимеразы (1 U/мкл) и 2 мкл выделенной ДНК (50 нг/мкл). Для мультилокусного межмикросателлитного анализа были использованы 14 полиморфных ISSR праймеров длиной 11-18 нуклеотидов. В результате проведенной оптимизации были выбраны следующие условия 
амплификации: предварительная денатурация при температуре $94{ }^{\circ} \mathrm{C}$ в течение 5 мин, последующие 35 циклов - денатурация $94{ }^{\circ} \mathrm{C}$ (1 мин), температура отжига в зависимости от использованного праймера (45 с), синтез - 5 мин при $72{ }^{\circ} \mathrm{C}$, финальный цикл элонгации при температуре $72{ }^{\circ} \mathrm{C}$ в течение 10 мин. Амплифрикацию проводили в программируемом термоциклере T100 (Applied Biosystems, USA). Электрофорез ПЦР-продуктов проводили в 2 \%-м агарозном геле с добавлением этидиум бромида и визуализировали под ультрафиолетовым светом с использованием гель-документирую-щей системы BioRad.

Таблица 1

Генотипы дикого граната, собранные в разных регионах Азербайджана

\begin{tabular}{|c|c|c|c|c|c|c|c|c|}
\hline $\begin{array}{l}\text { Ho- } \\
\text { мep }\end{array}$ & Место сбора & Код & $\begin{array}{l}\text { Ho- } \\
\text { мep }\end{array}$ & Место сбора & Код & $\begin{array}{l}\text { Ho- } \\
\text { мep }\end{array}$ & Место сбора & Код \\
\hline 1 & \multirow{15}{*}{ Агсу } & $\mathrm{A} 1$ & 31 & \multirow{15}{*}{ Исмаиллы } & И1 & 61 & \multirow{15}{*}{ Самух } & $\mathrm{Ca} 1$ \\
\hline 2 & & $\mathrm{~A} 2$ & 32 & & И2 & 62 & & Ca2 \\
\hline 3 & & A3 & 33 & & И3 & 63 & & Ca3 \\
\hline 4 & & A4 & 34 & & И4 & 64 & & $\mathrm{Ca} 4$ \\
\hline 5 & & A5 & 35 & & И5 & 65 & & Ca5 \\
\hline 6 & & A6 & 36 & & И6 & 66 & & Ca6 \\
\hline 7 & & A7 & 37 & & И7 & 67 & & $\mathrm{Ca} 7$ \\
\hline 8 & & A8 & 38 & & И8 & 68 & & Ca8 \\
\hline 9 & & A9 & 39 & & И9 & 69 & & Ca9 \\
\hline 10 & & $\mathrm{~A} 10$ & 40 & & И10 & 70 & & Ca10 \\
\hline 11 & & $\mathrm{~A} 11$ & 41 & & И11 & 71 & & Ca11 \\
\hline 12 & & $\mathrm{~A} 12$ & 42 & & И12 & 72 & & Ca12 \\
\hline 13 & & $\mathrm{~A} 13$ & 43 & & И13 & 73 & & Ca13 \\
\hline 14 & & $\mathrm{~A} 14$ & 44 & & И14 & 74 & & Ca14 \\
\hline 15 & & A15 & 45 & & И15 & 75 & & Ca15 \\
\hline 16 & \multirow{15}{*}{ Габала } & 「a1 & 46 & \multirow{15}{*}{ Гёйчай } & 「ё1 & 76 & \multirow{15}{*}{ Сабирабад } & $\mathrm{C} 1$ \\
\hline 17 & & Га2 & 47 & & 「ё2 & 77 & & $\mathrm{C} 2$ \\
\hline 18 & & Гa3 & 48 & & 「ё3 & 78 & & $\mathrm{C} 3$ \\
\hline 19 & & Га4 & 49 & & Гё4 & 79 & & C4 \\
\hline 20 & & 「а5 & 50 & & 「ё5 & 80 & & $\mathrm{C} 5$ \\
\hline 21 & & Гa6 & 51 & & 「ё6 & 81 & & $\mathrm{C} 6$ \\
\hline 22 & & 「а7 & 52 & & Гё7 & 82 & & C7 \\
\hline 23 & & Га8 & 53 & & Гё8 & 83 & & C8 \\
\hline 24 & & Га9 & 54 & & 「ё9 & 84 & & $\mathrm{Cg}$ \\
\hline 25 & & Га10 & 55 & & Гё10 & 85 & & C10 \\
\hline 26 & & Гa11 & 56 & & Гё11 & 86 & & C11 \\
\hline 27 & & Гa12 & 57 & & Гё12 & 87 & & C12 \\
\hline 28 & & Га13 & 58 & & Гё13 & 88 & & C13 \\
\hline 29 & & Га14 & 59 & & Гё14 & 89 & & C14 \\
\hline 30 & & Га15 & 60 & & Гё15 & 90 & & C15 \\
\hline
\end{tabular}

Статистическая обработка полученных данных. Анализ амплифицированных фрагментов был проведен с помощью компьютерной программы PAST [8]. Построение дендрограммы и оценка генетической близости между об- разцами проводили на основе индекса генетического сходства Жаккарда, кластеризация осуществлялась с помощью метода UPGMA.

Коэфффициент генетического разнообразия вычислялся согласно формуле Вейра [9]: 


$$
\text { ИГР }=1-\sum_{i}^{n} P_{\mathrm{I}}^{2},
$$

где ИГР - индекс генетического разнообразия; $\mathrm{Pi}$ - частота встречаемости аллелей.

Для анализа информационного полиморфизма были использованы некоторые статистические параметры: PIC [10].

Значение PIC для каждого локуса вычислялось согласно формуле, предложенной RoldanRuiz [11]:

$$
P I C=2 f_{i}\left(1-f_{i}\right)
$$

где $\mathrm{PIC}_{\mathrm{i}}$ - PIC для локуса $\mathrm{i} ; f_{\mathrm{i}}$ - частотавстречаемости амплифицированных фрагментов (присутствующие спектры); $\left(1-f_{i}\right)$ - частота встречаемости не амплифицированных фрагментов (отсутствующие спектры). Среднее значение

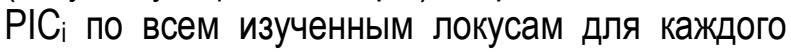
праймера дает нам величину PIC.

Результаты исследования и их обсуждение

ISSR полиморфизм

Тестирование 20 праймеров позволило выявить 14 наиболее эфффективных для дальнейшего анализа, с использованием которых было идентифицировано 110 фрагментов, из которых 86 (78 \%) оказались полиморфными, 24 (22\%) - мономорфными.

В среднем один праймер инициировал синтез 7,8 фррагментов. Наибольшее количество ампликонов было детектировано для праймера UBC 811. Количество полиморфных фррагментов ДНК варьировало от 3 до 9. Минимальное число идентифицировалось праймерами UBC 827 и UBC 857, максимальное - при амплификации ДНК с праймерами UBC 811 и UBC 840.

Среднее число полиморфных фррагментов на праймер составило 6,1. Определено варьирование количества полиморфных локусов в зависимости от праймера: от 57 до $100 \%$. В среднем уровень полиморфизма, выявленный ISSRанализом, составил $78 \%$. Для праймера UBC 811 и IS15 определен 100 \% уровень полиморфризма (табл. 2). В данном исследовании по каждому ISSR-локусу был вычислен индекс генетического разнообразия (ИГР). Среднее значение ИГР для всей изученной коллекции равнялось 0,77 . Высокие значения индекса были выявлены праймерами IS 15, UBC 811 и HB 14 (0,92; 0,90 и 0,90 соответственно).

ISSR-праймеры и их статистические параметры

Таблица 2

\begin{tabular}{|l|c|c|c|c|c|c|}
\hline \multicolumn{1}{|c|}{ Праймеры } & $\begin{array}{c}\text { Тип повторяющейся } \\
\text { последовательности }\end{array}$ & КАФ & КПФ & РІС & Полиморфизм, \% & ИГР \\
\hline UBC 808 & $(\mathrm{AG})_{8} \mathrm{C}$ & 8 & 7 & 0,39 & 88 & 0,70 \\
\hline UBC 810 & $(\mathrm{GA})_{8} \mathrm{~T}$ & 7 & 4 & 0,28 & 57 & 0,67 \\
\hline UBC 811 & $(\mathrm{GA})_{8} \mathrm{C}$ & 10 & 9 & 0,44 & 90 & 0,90 \\
\hline UBC 812 & $(\mathrm{GA})_{8} \mathrm{~A}$ & 7 & 5 & 0,36 & 71 & 0,83 \\
\hline UBC 827 & $(\mathrm{AC})_{8} \mathrm{G}$ & 5 & 3 & 0,28 & 60 & 0,33 \\
\hline UBC 834 & $(\mathrm{AG})_{8} \mathrm{YT}$ & 8 & 6 & 0,36 & 75 & 0,80 \\
\hline UBC 840 & $(\mathrm{GA})_{8}$ TT & 10 & 6 & 0,32 & 60 & 0,81 \\
\hline UBC 857 & $(\mathrm{AC})_{8} \mathrm{TT}$ & 5 & 3 & 0,34 & 60 & 0,70 \\
\hline UBC 868 & $(\mathrm{GAA})_{6}$ & 9 & 7 & 0,41 & 78 & 0,85 \\
\hline HB 14 & $(\mathrm{CTC})_{3} \mathrm{GC}$ & 8 & 7 & 0,43 & 88 & 0,90 \\
\hline ISSR 3 & $\mathrm{TGT}(\mathrm{AC})_{7} \mathrm{~A}$ & 7 & 5 & 0,40 & 71 & 0,70 \\
\hline ISSR 16 & $\mathrm{CGT(CA)})_{7} \mathrm{C}$ & 8 & 8 & 0,48 & 100 & 0,90 \\
\hline IS 11 & $(\mathrm{AGC})_{6} \mathrm{G}$ & 9 & 7 & 0,25 & 78 & 0,84 \\
\hline IS 15 & $(\mathrm{GA})_{8} \mathrm{CG}$ & 9 & 9 & 0,43 & 100 & 0,92 \\
\hline Bсего & - & 110 & 86 & - & - & - \\
\hline $\begin{array}{l}\text { Cреднее } \\
\text { значение }\end{array}$ & - & 7,8 & 6,1 & 0,39 & 78 & 0,77 \\
\hline
\end{tabular}


Изучение генетического разнообразия сортов и популяций дикого граната исследователи разных стран проводили с использованием различных молекулярных маркеров. Так, генетическое разнообразие популяций граната из Китая и культурных сортов Туниса было оценено с использованием AFLP, являющегося одним из наиболее широко используемых в исследованиях $[12,13]$. M. Talebi и др., используя 13 RAPDпраймеров для характеристики 28 генотипов граната из коллекции Йезд Ирана, выявили низкий уровень полиморфизма, объяснив это тем, что исследованные сорта были либо клонированы, либо вегетативно размножены [14]. Такие же результаты были получены Sarkhosh и др. [15], изучившими с использованием RAPDанализа генотипы граната из Ирана. Эфффективность исследования молекулярными маркерами оценивается выявленным им уровнем полиморфизма. ISSR относится к классу молекулярных маркеров, основанных на межтандемных повторах коротких ДНК последовательностей. Эти межмикросателлитные повторы выявляют высокий полиморфизм даже среди близкородственных генотипов, благодаря отсутствию фуннкциональных ограничений в этих не кодирующих регионах [16]. ISSR - эффрективный молекулярный маркер, характеризующий генетическую изменчивость в популяциях дикого граната [17].

В наших исследованиях все 14 ISSRпраймеров, апробированных нами, проявили себя полиморфными, т. е. эффективными для генотипирования образцов граната. В результате инициирования синтеза 110 фрагментов выявлен высокий уровень полиморфизма, составивший 78 \%. Полученные данные согласуются с результатами исследований Narzary и др., установивших с применением 17 ISSR-праймеров полиморфизм на уровне 76,5 \% [18]. Причина высокого полиморфизма межмикросателлитных маркеров может быть обусловлена их мультиаллельной природой и гипервариабельностью. Наибольшая частота встречаемости полиморфных локусов отмечена при использовании праймеров с динуклеотидным повтором (AG) 8 , использование которого позволило выявить $100 \%$ полиморфизм, что согласуется с исследованиями Carvalho и др., установившими эфффективность применения праймеров ISSR, включаю- щих повторы $(A G)_{n}$ [19]. Эффрективность использования ISSR-маркеров с целью определения полиморфизма ДНК отмечалась ранее и в других исследованиях. El Amine Ajal с сотрудниками [20], оценивая генетическое разнообразие 27 сортов граната из Марокко с помощью 8 ISSRпраймеров, выявили 70 фрагментов, 61 из которых были полиморфными. Индекс генетического расстояния Нея варьировал от 0,12 до 1 и в среднем был равен 0,67, что позволило сделать вывод об эффективности использования ISSRмаркеров для оценки полиморфизма и генетического разнообразия генотипов граната. В нашем исследовании по всем ISSR-локусам был вычислен индекс генетического разнообразия, среднее значение которого составило 0,67. Высокий показатель генетического разнообразия был выявлен праймерами UBC 812 и UBC 811 (0,83 и 0,90 соответственно). На информативность этих праймеров указывал и Z. Noormohammadi [21]. Полученные нами данные о высоком уровне ИГР свидетельствуют о богатом генетическом разнообразии коллекции граната, собранной из различных регионов Азербайджана.

Для оценки информационного полиморфизма был применен ряд статистических подходов. Маркерные системы различают по мере их информативности, что, в свою очередь, зависит от степени их полиморфизма. Одним из основных параметров, определяющих меру информативности маркеров, является величина информационного полиморфизма (PIC). Как известно, для доминантных маркеров значение РIC изменяется от 0 до 0,5, поскольку для такого типа маркеров допускается только два аллеля на локус и обе величины подвержены влиянию числа и частоты аллелей [22]. Из исследованных нами 86 полиморфных локусов наиболее информативными проявили себя $40\left(\mathrm{PIC}_{\mathrm{i}}>0,40\right)$. Наиболее высокий показатель PIC $(0,48)$ отмечен с применением праймера ISSR 16 с динуклеотидным повтором $(\mathrm{CA})_{7}$ (см. табл. 2). Для большинства изученных локусов выявлены средние значения РІС, которые колебались в пределах 0,25-0,44, средние и высокие показатели которых достаточны для идентификации и оптимальны для дифференциации изученных групп генотипов. 


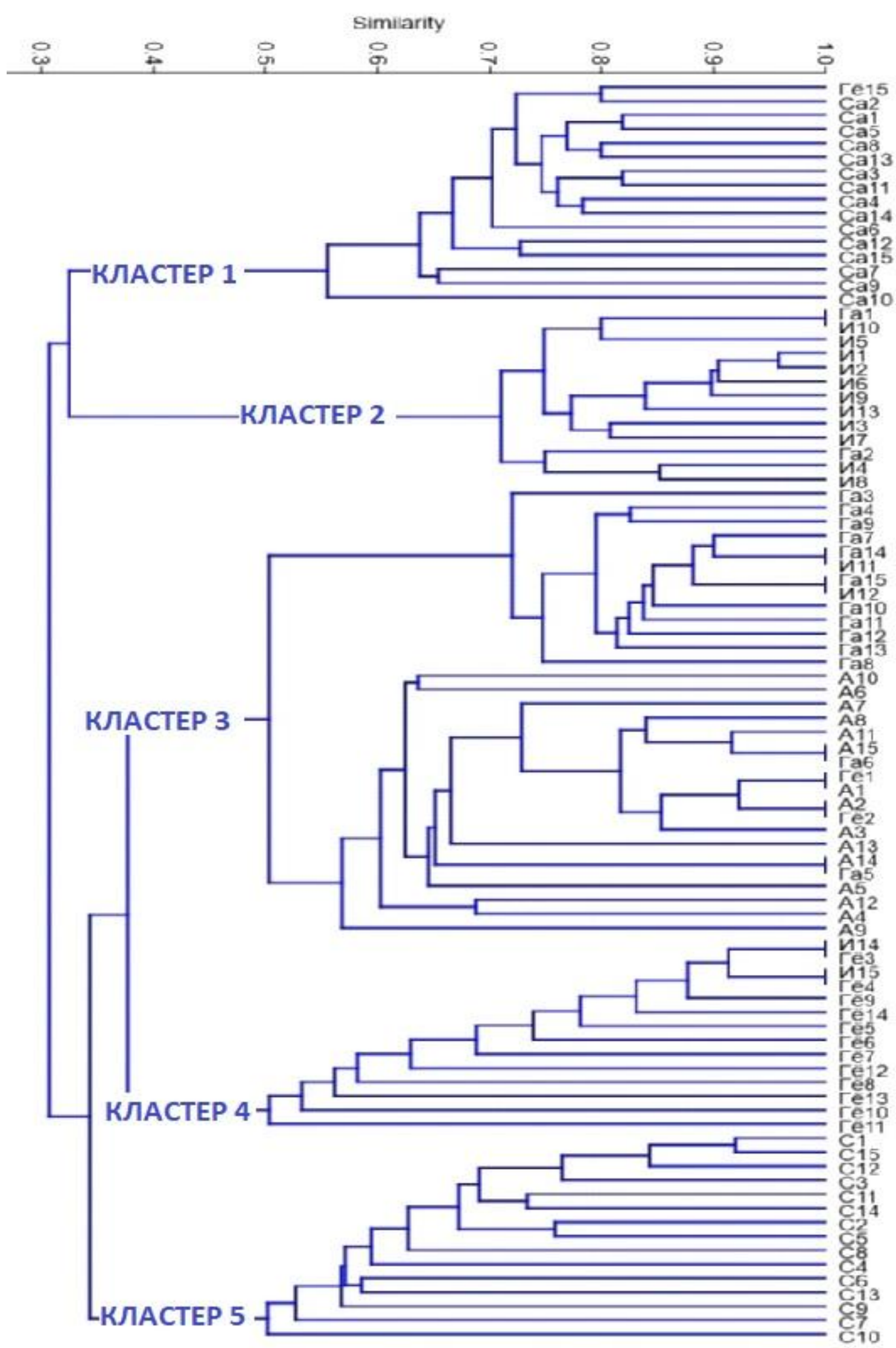

Дендрограмма, построенная по результатам ISSR-анализа на основе индекса генетического сходства Жаккарда 
Высокое значение PIC для ISSR-праймеров может быть объяснено высокой информативностью маркеров [23]. Полученные нами значения PIC значительно превышают подобные данные в исследованиях M. Talebi и др. [14], у которых среднее значение РІС было равно 0,163, находилось в пределах 0,099-0,257, a также D. Narzary и др. [18], у которых среднее значение было равно 0,15, находясь в пределах 0,120,21 . В исследованиях Z. Noormohammadi при изучении с помощью 6 ISSR-праймеров 36 генотипов граната значение PIC колебалось в пределах 0,272 (UBC 834) - 0,494 (UBC 811), что согласуется с нашими результатами [21].

Кластерный анализ позволил дифференцировать большинство исследованных образцов (рис.). Количество сгруппированных образцов на дендрограмме варьировалось от 14 до 32 . Наиболее многочисленным был кластер 3 , в котором было локализовано 32 образца, что составило 35 \% всех изученных генотипов. Следует отметить, что в этом кластере объединены генотипы, собранные в Агсуинском регионе. В этот кластер вошли также 13 из 15 генотипов граната, собранных в Габале. Третий кластер дендрограммы объединил 2 генотипа из Исмаиллы и генотипа из Гейчая.

Результаты кластерного анализа выявили группировку некоторых сортов в зависимости от места их сбора. Например, первый кластер представлен в основном генотипами Самухского района; преобладающее количество изученных сортов самухов (15 из 16) были объединены в первом кластере. Среди 19 генотипов, включенных во второй кластер, преобладают представители Исмаиллинского района. Все генотипы, сгруппированные в пятом кластере, были собраны из Агсу. Комбинация этих генотипов указывает на наличие сходных аллельных вариантов для большинства изученных интермикросателлитных локусов. В исследованиях M. Talebi c сотрудниками при анализе молекулярной вариации ISSR существенной корреляции между географическими регионами и генетической структурой изученных образцов граната не отмечали. При этом значение индекса сходства колебалось в пределах 0,291-0,930 и в среднем было равно 0,674 [24]. В нашем исследовании коэфффициент жаккардового сходства варьировался от 0,03 до 1,00 со средним значением 0,77 .
Заключение. Настоящее исследование показывает, что разнообразие существует в зародышевой плазме дикого граната, собранной в Азербайджане. С тех пор наблюдалось большое количество генетического разнообразия в растениях, что в дальнейшем привело к легкой адаптации растений к различным условиям окружающей среды. Исследования по молекулярному анализу различных генотипов могут также привести к установлению филогенетических отношений внутри генотипов, принадлежащих к одному или разным местам. Это также поможет понять процесс одомашнивания в ближайшем будущем.

\section{Литература}

1. Teixeira da Silva J., Rana T.S., Narzaryd D. et al. Pomegranate biology and biotechnology /I A review. Sci. Hort. 2013. V. 160. P. 85-107.

2. Al-Zoreky N.S. Antimicrobial activity of pomegranate (Punica granatum L.) fruit peels // Int J. Food Microbiol. 2009. V. 134. P. 244-8.

3. Zamani Z., Sarkhosh A., Fatahi R., Ebadi A. Genetic relationships among pomegranate genotypes studied by fruit characteristics and RAPD markers // J. Hort Sci Biotechnol. 2007. V. 82. P. 11-18.

4. Kazemialamuti M., Zeinalabedini M., Derazmahalleh M.M. et al. Extensive genetic diversity in Iranian pomegranate (Punica granatum L.) germplasm revealed by microsatellite markers // Sci Hort. 2012. V. 146. P. 104-114.

5. Ajal E.A., Jbir R., Melgarejo P. et al. Efficiency of Inter Simple Sequence Repeat (ISSR) markers for the assessment of genetic diversity of Moroccan pomegranate (Punica granatum L.) cultivars // Biochem. Syst. Ecol. 2014. V. 56. P. 24-31.

6. Aliyev R.T., Abbasov M.A., Mammadov A.C. Genetic identification of diploid and tetraploid wheat species with RAPD marker // Turk. J. Biol. 2007. V. 31. P. 173-180.

7. Doyle J.L., Doyle J.J. A rapid DNA isolation procedure for small quantities of fresh leaf tissue // Phytochem. Bull. 1987. V. 19. P. 11-15.

8. Hammer O., Harper D.A., Ryan P.D. Past: paleontological statistics software package for education and data analysis // Palaeontologia Electronica. 2001. V. 4. P. 1-9. 
9. Weir B.S. Genetic Data Analysis Methods for Discrete Genetic Data. Sunderland, MA, USA: Sinauer Assoc. Inc., 1990.

10. Чесноков Ю.Ф. Оценка меры информационного полиморфизма генетического разнообразия // Сельскохозяйственная биология. 2015. Т . 5. С. 571-578.

11. Roldan-Ruiz I., Dendauw J., Vanbockstaele E. et al. AFLP markers reveal high polymorphic rates in ryegrasses (Lolium spp.) // Mol. Breed. 2000. V. 6. P. 125-134.

12. Yuan Z., Yin Y., Qu J., Zhu L. Population genetic diversity in Chinese pomegranate (Punica granatum L.) cultivars revealed by fuorescent-AFLP markers // J. Genet. Genom. 2007. V. 34. P. 1061-1071.

13. Jbir R., Hasnaoui N., Mars M. et al. Characterization of Tunisian pomegranate (Punica granatum L.) cultivars using amplified fragment length polymorphism analysis // Sci. Hortic. 2008. V. 115. P. 231-237.

14. Talebi M., Bahar M., Sharifnabi B., Yamchi A. Evaluation of genetic diversity among Iranian pomegranate (Punica granatum L.) cultivars, using ISSR and RAPD markers // Taxonomy and Biosystematics. 2011. V. 8. P. 35-44.

15. Sarkhosh A., Zamani Z., Fatahi R., Ebadi A. RAPD markers reveal polymorphism among some Iranian pomegranate (Punica granatum L.) genotypes // Scientia Horti culturae. 2006. V. 111. P. 24-29.

16. Omayma M.I., Rania A.A., Ibrahim A.M. Morphological and molecular evaluation of some Egyptian pomegranate cultivars // African Journal of Biotechnology. 2014. V. 13. P. 226-237.

17. Zahra N., Ali F., Saeed H-R. et al. Genetic variation among Iranian pomegranates (Punica granatum L.) using RAPD, ISSR and SSR markers // Aust. J. Crop Sci. 2012. V. 6 (2). P. 268-275.

18. Narzary D., Rana T.S., Ranade S.A. Molecular analysis of genetic diversity in Indian pomegranates using RAPD, DAMD and ISSR // Fruit, vegetable and cereal science and Biotechnology. 2010. V. 4. P. 126-143.

19. Carvalho A., Brito J.L., Macas B., Pinto H.G. Genetic variability analysis of a collection of Old Portuguese bread wheat using ISSRs // Options Mediterraneennes. Ser. A. Sem. Medit. 2008. V. 81. P. 35-38.
20. El Amine Ajal, Rania Jbir, Pilar Legua et al. Genetic diversity of Moroccan pomegranate (Punica Granatum L.) cultivars using AFLP markers // Australian Journal of Crop Science. 2015. V. 9. P. 22-29.

21. Noormohammadi Z., Fasihee A., HomaeeRashidpoor S. et al. Genetic variation among Iranian pomegranates (Punica granatum L.) using RAPD, ISSR and SSR markers // Australian Journal of Crop Science. 2012. V. 6. P. 268-275.

22. Botstein D., White R.L., Skalnick M.H., Davies $R$.W. Construction of a genetic linkage map in man using restriction fragment length polymorphism // Am. J. Hum. Genet. 1980. V. 32. P. 314-331.

23. Najaphy A., Ashrafi Parchin R., Farshadfar E. Evaluation of genetic diversity in wheat cultivars and breeding lines using inter simple sequence repeat markers // Biotechnology \& biotechnological equipment. 2011. V. 25. P. 2634-2638.

24. Talebi B.M., Sharifi N.B., Bahar M. Analysis of genetic diversity in pomegranate cultivars of Iran, using Random Amplified Polymorphic DNA (RAPD) markers // Proceedings of the Third National Congressof Biotechnology. 2003. V. 2. P. 343-345.

\section{Literatura}

1. Teixeira da Silva J., Rana T.S., Narzaryd D. et al. Pomegranate biology and biotechnology /I A review. Sci. Hort. 2013. V. 160. P. 85-107.

2. Al-Zoreky N.S. Antimicrobial activity of pomegranate (Punica granatum L.) fruit peels // Int J. Food Microbiol. 2009. V. 134. P. 244-8.

3. Zamani Z., Sarkhosh A., Fatahi R., Ebadi A. Genetic relationships among pomegranate genotypes studied by fruit characteristics and RAPD markers // J. Hort Sci Biotechnol. 2007. V. 82. P. 11-18.

4. Kazemialamuti M., Zeinalabedini M., Derazmahalleh M.M. et al. Extensive genetic diversity in Iranian pomegranate (Punica granatum L.) germplasm revealed by microsatellite markers // Sci Hort. 2012. V. 146. P. 104-114.

5. Ajal E.A., Jbir R., Melgarejo P. et al. Efficiency of Inter Simple Sequence Repeat (ISSR) markers for the assessment of genetic diversity of Moroccan pomegranate (Punica 
granatum L.) cultivars // Biochem. Syst. Ecol. 2014. V. 56. P. 24-31.

6. Aliyev R.T., Abbasov M.A., Mammadov A.C. Genetic identification of diploid and tetraploid wheat species with RAPD marker // Turk. J. Biol. 2007. V. 31. - P. 173-180.

7. Doyle J.L., Doyle J.J. A rapid DNA isolation procedure for small quantities of fresh leaf tissue // Phytochem. Bull. 1987. V. 19. P. 11-15.

8. Hammer O., Harper D.A., Ryan P.D. Past: paleontological statistics software package for education and data analysis // Palaeontologia Electronica. 2001. V. 4. P. 1-9.

9. Weir B.S. Genetic Data Analysis Methods for Discrete Genetic Data. Sunderland, MA, USA: Sinauer Assoc. Inc., 1990.

10. Chesnokov Ju.F. Ocenka mery informacionnogo polimorfizma geneticheskogo raznoobrazija // Sel'skohozjajstvennaja biologija. 2015. T. 5. S. 571-578.

11. Roldan-Ruiz I., Dendauw J., Vanbockstaele E. et al. AFLP markers reveal high polymorphic rates in ryegrasses (Lolium spp.) // Mol. Breed. 2000. V. 6. P. 125-134.

12. Yuan Z., Yin Y., Qu J., Zhu L. Population genetic diversity in Chinese pomegranate (Punica granatum L.) cultivars revealed by fuorescent-AFLP markers // J. Genet. Genom. 2007. V. 34. P. 1061-1071.

13. Jbir R., Hasnaoui N., Mars M. et al. Characterization of Tunisian pomegranate (Punica granatum L.) cultivars using amplified fragment length polymorphism analysis // Sci. Hortic. 2008. V. 115. P. 231-237.

14. Talebi M., Bahar M., Sharifnabi B., Yamchi A. Evaluation of genetic diversity among Iranian pomegranate (Punica granatum L.) cultivars, using ISSR and RAPD markers // Taxonomy and Biosystematics. 2011. V. 8. P. 35-44.

15. Sarkhosh A., Zamani Z., Fatahi R., Ebadi A. RAPD markers reveal polymorphism among some Iranian pomegranate (Punica granatum L.) genotypes // Scientia Horticulturae. 2006. V. 111. P. 24-29.

16. Omayma M.I., Rania A.A., Ibrahim A.M. Morphological and molecular evaluation of some
Egyptian pomegranate cultivars // African Journal of Biotechnology. 2014. V. 13. P. 226-237.

17. Zahra N., Ali F., Saeed H-R. et al. Genetic variation among Iranian pomegranates (Punica granatum L.) using RAPD, ISSR and SSR markers // Aust. J. Crop Sci. 2012. V. 6 (2). P. 268-275.

18. Narzary D., Rana T.S., Ranade S.A. Molecular analysis of genetic diversity in Indian pomegranates using RAPD, DAMD and ISSR // Fruit, vegetable and cereal science and Biotechnology. 2010. V. 4. P. 126-143.

19. Carvalho A., Brito J.L., Macas B., Pinto H.G. Genetic variability analysis of a collection of Old Portuguese bread wheat using ISSRs // Options Mediterraneennes. Ser. A. Sem. Medit. 2008. V. 81. P. 35-38.

20. El Amine Ajal, Rania Jbir, Pilar Legua et al. Genetic diversity of Moroccan pomegranate (Punica granatum L.) cultivars using AFLP markers // Australian Journal of Crop Science. 2015. V. 9. P. 22-29.

21. Noormohammadi Z., Fasihee A., HomaeeRashidpoor S. et al. Genetic variation among Iranian pomegranates (Punica granatum L.) using RAPD, ISSR and SSR markers // Australian Journal of Crop Science. 2012. V. 6. P. 268-275.

22. Botstein D., White R.L., Skalnick M.H., Davies $R$.W. Construction of a genetic linkage map in man using restriction fragment length polymorphism // Am. J. Hum. Genet. 1980. V. 32. P. 314-331.

23. Najaphy A., Ashrafi Parchin R., Farshadfar E. Evaluation of genetic diversity in wheat cultivars and breeding lines using inter simple sequence repeat markers // Biotechnology \& biotechnological equipment. 2011. V. 25. P. 2634-2638.

24. Talebi B.M., Sharifi N.B., Bahar M. Analysis of genetic diversity in pomegranate cultivars of Iran, using Random Amplified Polymorphic DNA (RAPD) markers // Proceedings of the Third National Congress of Biotechnology. 2003. V. 2. P. 343-345. 